\section{Genetische Ursachen geistiger Behinderung}

Die geistige Behinderung betrifft etwa 0,5\% der Bevölkerung in westlichen Ländern. Die klinische Diagnose beruht im wesentlichen auf einem IQ von weniger als 50. Eine Gruppe von Genetikern hat nun das Genom von 100 geistig Behinderten auf mögliche Veränderungen untersucht.

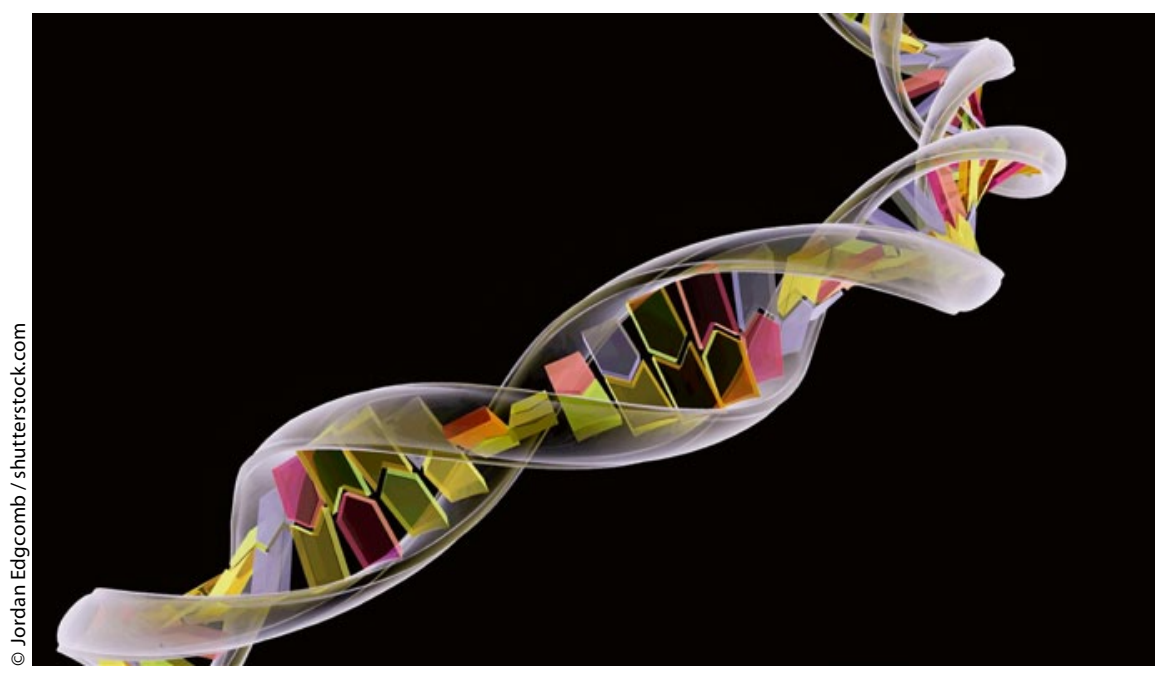

Spontane Mutationen sind ein häufiger Grund für geistige Behinderung.

inder mit unterschiedlichen nichtsyndromalen Formen geistiger Behinderung sind klinisch nicht unterscheidbar. Neben Infektionen und perinataler Asphyxie wird davon ausgegangen, dass die meisten Formen geistiger Behinderung genetische Ursachen haben. Es zeigte sich aber, dass diese bei etwa $60 \%$ der Patienten bislang nicht aufzudecken waren. Wird eine genetische Ursache einer geistigen Behinderung nachgewiesen, so hat dies für den Patienten und seine Familie Vorteile: Die Prognose kann besser gestellt und damit u. U. unnötige invasive Diagnostik vermieden werden. Auch lässt sich das Wiederholungsrisiko richtig einschätzen.

Die Tatsache, dass geistige Behinderung nicht selten sporadisch ohne erkennbare familiäre Faktoren auftritt, hat die Hypothese begründet, dass ein großer Teil dieser Fälle durch spontane Mutationen ausgelöst sind. Da bei den meisten Patienten ein klinischer Phänotyp fehlt, erschien es einer Arbeitsgruppe um Joep de Ligt aus Nijmegen, Niederlande notwendig, bei 100 Patienten mit geistiger Behinderung und unklarer Diagnose sowie deren Eltern die Gesamtheit der
Effekt auf den Aminosäurelevel und das Gehirnexpressionsmuster. Die Arbeitsgruppe hatte bereits bei 765 Patienten mit geistiger Behinderung eine Reihe von Kandidatengenen ermittelt.

Die Wissenschaftler konnte belegen, dass bei 53 der 100 Patienten eine spontane Mutation vorlag. Zusammengenommen war bei 16 von 100 Patienten eine Diagnosestellung möglich. In zwei Fällen hatte die Diagnose unmittelbare therapeutische Auswirkungen für den Patienten: Bei einem wurde eine ketogene Diät empfohlen, bei einem weiteren führte die Vermeidung von Natriumkanal-blockierenden Medikamenten zu einer besseren Anfallskontrolle.

de Ligt J et al. Diagnostic exome sequencing in persons with severe intellectual disability. N Engl J Med 2012 Oct 3. [Epub ahead of print]

Kommentar: Eine diagnostische Ausbeute von $16 \%$ bei Patienten mit bislang nicht einzuordnender Ursache einer geistigen Behinderung ist ermutigend. Jeder, der als Arzt Umgang mit diesen Patienten und dessen Eltern hat, weiß, welch große Erleichterung es für alle bedeutet, wenn eine eindeutige Diagnose gestellt ist, die in der Regel mit der Feststellung eines praktisch fehlenden Wiederholungsrisiko verbunden ist. Die vorgestellten Untersuchungsverfahren sind zwar gegenwärtig noch ziemlich aufwendig und teuer. Die Fortschritte in der Automatisierung der DNA-Analyse machen es jedoch wahrscheinlich, dass der Eingang dieser Methoden in die Routinediagnostik nicht mehr lange auf sich warten lassen wird.

Dr. Hartmut Koch

\section{Suizidgedanken bei Jugendlichen}

Körperliche und seelische Gewalt führt bei Jugenldichen häufig zu Selbstmordgedanken. Diese Gefahr ist besonders hoch, wenn die Gewalt von den Eltern ausgeht, wie eine Analyse des National Survey of Children's Exposure to Violence ergeben hat. Demnach hatten von knapp 1.200 Jugendlichen im Alter zwischen zehn und 17 Jahren mehr als $4 \%$ im vergangenen Monat mindestens einmal ernsthaft mit dem Gedanken gespielt, sich das Leben zu nehmen. Die wichtigste Rolle kam dabei den Eltern zu: Wer von diesen geschlagen, gedemütigt, drangsaliert, mit Liebesentzug bestraft, vernachlässigt oder eingesperrt worden war, wollte mit 4,5-mal höherer Wahrscheinlichkeit aus dem Leben scheiden als Jugendliche ohne solche Erfahrungen. Dr. Elke Oberhofer

Turner HA et al. Recent victimization exposure and suicidal ideation in adolescents. Arch Pediatr Adolesc Med 2012; Oktober 22; doi: 10.1001/archpediatrics.2012.1549 